\title{
Promising Effects of Benralizumab on Chronic Eosinophilic Pneumonia
}

\author{
Kohsuke Isomoto ${ }^{1,2}$, Tomohisa Baba ${ }^{1}$, Akimasa Sekine ${ }^{1}$, Naoto Aiko ${ }^{1}$ and Takashi Ogura ${ }^{1}$
}

\begin{abstract}
:
We herein report a case of refractory chronic eosinophilic pneumonia (CEP) complicated with uncontrolled bronchial asthma, in which remission was successfully induced with single dose of benralizumab, a monoclonal antibody against the alpha-chain of the interleukin-5 receptor. Resolution of the patient's symptoms and consolidation on chest X-ray were observed at 2 weeks and lasted for 8 weeks after the administration of benralizumab. Benralizumab would be a novel alternative choice of treatment for CEP patients who are at risk of potential toxicity due to long-term corticosteroid therapy.
\end{abstract}

Key words: bronchial asthma, chronic eosinophilic pneumonia, CEP, benralizumab, IL-5

(Intern Med 59: 1195-1198, 2020)

(DOI: 10.2169/internalmedicine.3606-19)

\section{Introduction}

Chronic eosinophilic pneumonia (CEP), which was first described as a distinct entity by Carrington et al. (1), is defined as an idiopathic condition characterized by the infiltration of eosinophils in the interstitium and alveoli of the lung (2). The mainstay of treatment is systemic corticosteroids, with usual doses of prednisone ranging from 20 to 60 $\mathrm{mg} /$ day (3), which leads to drastic improvement. Although there is no consensus on the optimal duration of therapy, Marchand et al. recommended at least 6 months based on a retrospective analysis (4). Because of the long-term detrimental effects of prolonged systemic glucocorticoid therapy, dose reduction is essential, despite a high rate of relapse. Recent advances in understanding eosinophil biology and drug design have enabled the targeting of interleukin (IL) -5 or IL-5 receptor $\alpha$ in the treatment of eosinophilic respiratory disorders. The efficacy and safety in of benralizumab a monoclonal antibody against IL-5 receptor $\alpha$ - through the elimination of eosinophils by an antibody-dependent cellular cytotoxic effect have been demonstrated in severe asthma patients with elevated eosinophil levels $(5,6)$. In the present report, we describe a case of refractory CEP complicated with uncontrolled bronchial asthma, in which remission was successfully induced with a single dose of benralizumab without the use of corticosteroids.

\section{Case Report}

A 58-year-old woman was evaluated during a routine follow-up visit. Her notable medical history included step 5 bronchial asthma, which had been diagnosed 18 years previously, eosinophilic otitis media and refractory CEP. The diagnosis of CEP had been pathologically confirmed two years previously by transbronchial lung biopsy together with clinical symptoms, peripheral blood eosinophilia (up to $14.2 \%$ ), and peripheral patchy ground glass opacities on chest radiography, which promptly responded to systemic glucocorticoid therapy. At the time of the initial diagnosis of CEP, bronchoalveolar lavage could not be performed due to her unstable respiratory status. A screening panel for allergic bronchopulmonary aspergillosis (ABPA) (including Aspergillus-specific IgE and Aspergillus fumigatus serum precipitins) was negative. Furthermore, bronchial washing culture yielded no bacteria or fungus. Antineutrophil cytoplasmic antibodies were also negative without any signs or symptoms compatible with vasculitis. She had experienced three exacerbations of asthma and CEP in the last year, with the third exacerbation occurring two months previously. All

${ }^{1}$ Department of Respiratory Medicine, Kanagawa Cardiovascular and Respiratory Center, Japan and ${ }^{2}$ Department of Medical Oncology, Kindai University Faculty of Medicine, Japan

Received: July 2, 2019; Accepted: December 4, 2019; Advance Publication by J-STAGE: February 1, 2020

Correspondence to Dr. Kohsuke Isomoto, lotus37.m3@gmail.com 


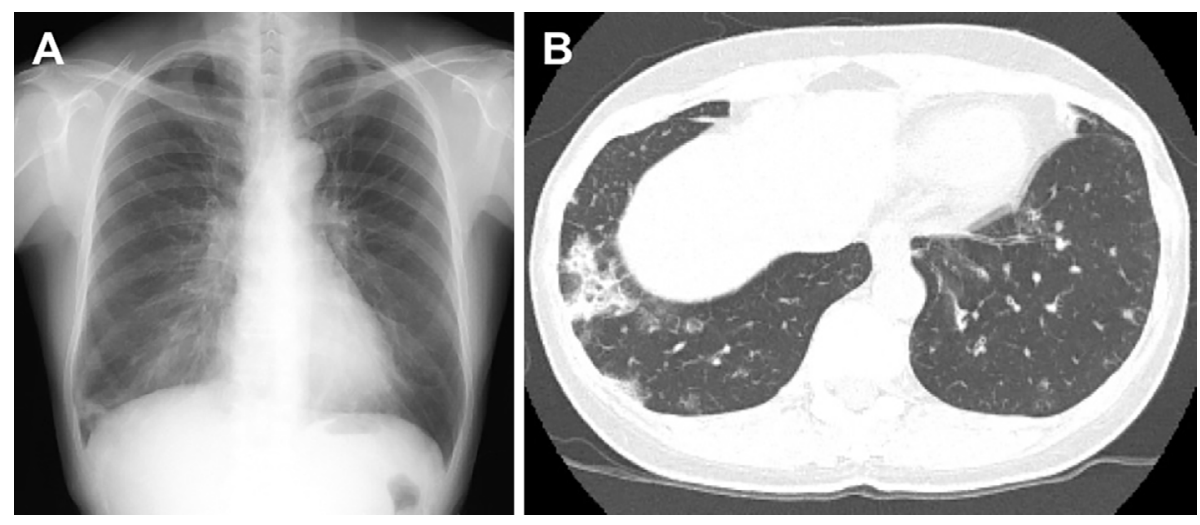

Figure 1. A chest radiograph (A) and computed tomography scan (B) obtained prior to the administration of benralizumab demonstrated consolidation of the right lower lobe.

three of these exacerbations were successfully treated with a 5-day course of oral prednisone (20 mg/day). Her eosinophilic otitis media was treated with oral betamethasone-dchlorpheniramine maleate as-needed. She did not take daily prednisone and her medications included the use of a combination inhaler with fluticasone $(500 \mu \mathrm{g})$ and salmeterol (50 $\mu \mathrm{g}$ ), twice daily, a salbutamol metered-dose inhaler (asneeded), and montelukast.

On examination, she reported breathlessness; however, a pulmonary examination revealed no wheezing or crackles. Her oxygen saturation on ambient air was $96 \%$ and her other vital signs were normal. Chest radiography revealed right lower lobe infiltration (Fig. 1A), and chest CT showed consolidation of the right lower lobe (Fig. 1B). A laboratory analysis revealed eosinophilia (white blood cell count, $6,910 / \mu \mathrm{L}$ with $1,112 / \mu \mathrm{L}$ ) and elevated immunoglobulin $\mathrm{E}$ (IgE, $866 \mathrm{IU} / \mathrm{mL}$ ). A pulmonary function test demonstrated low levels of forced expiratory volume in one second (FEV 1) and FEV1/forced vital capacity (FVC). The other findings are shown in Table. Based on the clinical manifestations, laboratory data, pulmonary function test results, and radiographic findings, we considered that the patient's condition was due to an exacerbation of CEP. As her asthma had been also uncontrolled, even with multiple drugs, and frequently required the high-dose administration of systemic glucocorticoids and there was concern of an exacerbation of asthma, we administered $30 \mathrm{mg}$ of benralizumab subcutaneously without systemic corticosteroid therapy. On re-evaluation at two weeks, she reported gradual resolution of her dyspnea, as well as the symptoms associated with eosinophilic otitis media. The consolidation on chest radiography had apparently disappeared (Fig. 2) and the laboratory data showed the complete depletion of the eosinophil count (white blood cell count, $3,370 / \mu \mathrm{L}$ with $0 / \mu \mathrm{L}$ ). Although a pulmonary function test showed no significant changes in FEV1 or FEV1/FVC (Table), her fractional exhaled nitric oxide level had improved (102 ppb to $86 \mathrm{ppb}$ ). She refused a scheduled second administration of benralizumab at 4 weeks due to her financial situation. On a follow-up visit at 8 weeks after treatment, chest radiography remained clear and laboratory data showed a slightly elevated peripheral eosinophil count (white blood cell count, 3,320/ $\mu \mathrm{L}$ with $10 / \mu \mathrm{L}$ ). She reported no clinical symptoms and was otherwise normal in a physical examination. At 16 weeks after administration, her eosinophilic otitis media deteriorated without any respiratory symptoms. Laboratory data showed an elevated eosinophil count (white blood cell count, 5,310/ $\mu \mathrm{L}$ with $998 / \mu \mathrm{L}$ ), which might suggest tentative response on benralizumab.

\section{Discussion}

Given the significant toxicity associated with long-term corticosteroid use (7), alternative therapies have been explored to minimize avoidable potential side effects in the management of CEP. Indeed, several biologic agents, such as omalizumab (8), mepolizumab $(9,10)$, and dupilumab (11), have already been shown to have clinical benefits in the treatment of sporadic CEP. In this article, we reported a notable case of refractory bronchial asthma complicated with CEP, in which remission was successfully induced with a single dose of subcutaneous benralizumab (30 $\mathrm{mg}$ ) without the use of systemic corticosteroids. To our knowledge, this is the first case of CEP to be treated with benralizumab. Recent studies have reported that IL-5 released by both T helper 2 and group 2 innate lymphoid cells significantly contributes to the airway eosinophilopoietic processes $(12,13)$. Much of the pathogenesis of CEP remains unknown, however, it could be argued that IL-5mediated eosinophil recruitment in the alveoli plays an important role in the development of CEP. Benralizumab is therefore a reasonable therapy for patients with CEP to the point that it neutralizes the function of IL- 5 by binding the alpha subunit of the IL-5 receptor and induces apoptosis of eosinophils via antibody-dependent cell-mediated cytotoxicity (5). This biologic agent also reportedly produced a reduction in the peripheral blood and mucosa/submucosa eosinophil levels after the intravenous administration of a single dose, which lasted at least 8 weeks at doses of 0.03 to $0.1 \mathrm{mg} / \mathrm{kg}$ and at least 12 weeks at doses of 0.3 to $3 \mathrm{mg} /$ $\mathrm{kg}(14,15)$. In the present case, the resolution of the pa- 
Table. Laboratory Data and Pulmonary Function Test.

\begin{tabular}{|c|c|c|c|c|}
\hline & Day 1 & 2 weeks & 8 weeks & 16 weeks \\
\hline \multicolumn{5}{|c|}{ Haematology and biochemistry } \\
\hline WBC & 6,910 & 3,370 & 3,320 & $5,310 / \mu \mathrm{L}$ \\
\hline Neutrophils & 59.4 & 58.8 & 54.2 & $52.5 \%$ \\
\hline Lymphocytes & 19.4 & 34.4 & 38 & $23 \%$ \\
\hline Monocyte & 4.5 & 6.8 & 7.2 & $4.9 \%$ \\
\hline Eosinophils & 16.1 & 0 & 0.3 & $18.8 \%$ \\
\hline Basophils & 0.6 & 0 & 0.3 & $0.8 \%$ \\
\hline $\mathrm{RBC}$ & $437 \times 10^{4}$ & $420 \times 10^{4}$ & $397 \times 10^{4}$ & $427 \times 10^{4} / \mu \mathrm{L}$ \\
\hline Hemoglobin & 12.8 & 12.5 & 11.8 & $12.7 \mathrm{~g} / \mathrm{dL}$ \\
\hline $\mathrm{MCV}$ & 89.7 & 89.5 & 92.7 & $91.6 \mathrm{fL}$ \\
\hline Platelet & $26.9 \times 10^{4}$ & $25.6 \times 10^{4}$ & $20.1 \times 10^{4}$ & $23.7 \times 10^{4} / \mu \mathrm{L}$ \\
\hline Total protein & 7.3 & 7.6 & 7.0 & $7.2 \mathrm{~g} / \mathrm{dL}$ \\
\hline Albumin & 4.4 & 4.5 & 3.9 & $4.1 \mathrm{~g} / \mathrm{dL}$ \\
\hline AST & 31 & 32 & 27 & $27 \mathrm{U} / \mathrm{L}$ \\
\hline ALT & 18 & 21 & 19 & $20 \mathrm{U} / \mathrm{L}$ \\
\hline LDH & 207 & 202 & 187 & $196 \mathrm{U} / \mathrm{L}$ \\
\hline ALP & 266 & 286 & 235 & $247 \mathrm{U} / \mathrm{L}$ \\
\hline$\gamma$-GTP & 18 & 16 & 16 & $17 \mathrm{U} / \mathrm{L}$ \\
\hline BUN & 16 & 18.1 & 19.4 & $15.8 \mathrm{mg} / \mathrm{dL}$ \\
\hline Creatinine & 0.52 & 0.53 & 0.59 & $0.59 \mathrm{mg} / \mathrm{dL}$ \\
\hline $\mathrm{Na}$ & 145 & 143 & 143 & $141 \mathrm{mEq} / \mathrm{L}$ \\
\hline K & 4.6 & 4.7 & 4.2 & $4.2 \mathrm{mEq} / \mathrm{L}$ \\
\hline $\mathrm{Cl}$ & 106 & 108 & 108 & $106 \mathrm{mEq} / \mathrm{L}$ \\
\hline CRP & 0.22 & 0.05 & 0.04 & $0.13 \mathrm{mg} / \mathrm{dL}$ \\
\hline KL-6 & 275 & 289 & 270 & $275 \mathrm{U} / \mathrm{mL}$ \\
\hline SP-D & 128.3 & 96.6 & 105 & $90.6 \mathrm{ng} / \mathrm{mL}$ \\
\hline $\operatorname{IgE}$ & 866 & 774 & 735 & $856.6 \mathrm{U} / \mathrm{mL}$ \\
\hline \multicolumn{5}{|c|}{ Pulmonary function test } \\
\hline FVC & 2.6 & 2.72 & & $\mathrm{~L}$ \\
\hline FEV1 & 1.58 & 1.59 & & $\mathrm{~L}$ \\
\hline FEV1 / FVC & 60.8 & 58.5 & & $\%$ \\
\hline FENO & 102 & 86 & & $\mathrm{ppb}$ \\
\hline
\end{tabular}

WBC: white blood cell, RBC: red blood cell, MCV: mean corpuscular volume, AST: aspartate aminotransferase, ALT: alanine aminotransferase, LDH: lactate dehydrogenase, ALP: alkaline phosphatase, $\gamma$-GTP: $\gamma$-glutamyltranspeptidase, BUN: blood urea nitrogen, SP-D: surfactant protein D, FVC: forced vital capacity, FEV1: forced expiratory volume in one second, FENO: fractional exhaled nitric oxide

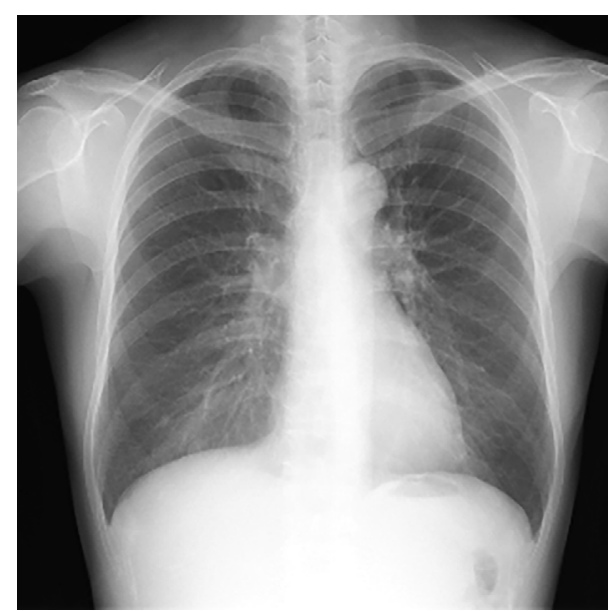

Figure 2. A chest radiograph on re-evaluation at two weeks showed the resolution of consolidation. tient's symptoms and consolidation on chest X-ray were observed at 2 weeks and the effects lasted for at least 8 weeks. Although we could not repeat the administration of benralizumab in this case, maintenance use might be a novel alternative option for the management of CEP.

In conclusion, benralizumab might be an alternative treatment option for patients with CEP who have steroidsensitive comorbidities or steroid-induced complications. Further studies in more patients are needed to confirm its effectiveness.

The authors state that they have no Conflict of Interest (COI).

\section{References}

1. Carrington $\mathrm{CB}$, Addington WW, Goff AM, et al. Chronic eosinophilic pneumonia. N Eng J Med 280: 787-798, 1969. 
2. Allen JN, Davis WB. Eosinophilic lung diseases. Am J Respir Crit Care Med 150: 1423-1438, 1994.

3. Cottin V, Cordier J-F. Eosinophilic pneumonias. Allergy 60: 841857, 2005.

4. Marchand E, Reynaud-Gaubert M, Lauque D, Durieu J, Tonnel $\mathrm{AB}$, Cordier JF. The Groupe d'Etudes et de Recherche sur les Maladies "Orphelines" Pulmonaires (GERM"O"P) Idiopathic chronic eosinophilic pneumonia. A clinical and follow-up study of 62 cases. Medicine (Baltimore) 77: 299-312, 1998.

5. Kolbeck R, Kozhich A, Koike M, et al. MEDI-563, a humanized anti-IL-5 receptor alpha mAb with enhanced antibody-dependent cell-mediated cytotoxicity function. J Allergy Clin Immunol 125: 1344-1353, 2010.

6. Bleecker ER, FitzGerald JM, Chanez P, et al. Efficacy and safety of benralizumab for patients with severe asthma uncontrolled with high-dosage inhaled corticosteroids and long-acting $\beta 2$-agonists (SIROCCO): a randomised, multicentre, placebo-controlled phase 3 trial. Lancet 388: 2115-2127, 2016.

7. Curtis JR, Westfall AO, Allison J, et al. Population-based assessment of adverse events associated with long-term glucocorticoid use. Arthritis Rheum 55: 420-426, 2006.

8. Kaya H, Gümüş S, Uçar E, et al. Omalizumab as a steroid-sparing agent in chronic eosinophilic pneumonia. Chest 142: 513-516, 2012.

9. Lin RY, Santiago TP, Patel NM. Favorable response to asthmadosed subcutaneous mepolizumab in eosinophilic pneumonia. J
Asthma 56: 1193-1197, 2019.

10. To M, Kono Y, Yamawaki S, et al. A case of chronic eosinophilic pneumonia successfully treated with mepolizumab. J Allergy Clin Immunol Pract 6: 1746-1748, 2018.

11. Menzella F, Montanari G, Patricelli G, et al. A case of chronic eosinophilic pneumonia in a patient treated with dupilumab. Ther Clin Risk Manag 15: 869-875, 2019.

12. Fulkerson PC, Rothenberg ME. Targeting eosinophils in allergy, inflammation and beyond. Nature Reviews Drug Discovery 12: 117-129, 2013.

13. Yanagibashi T, Satoh M, Nagai Y, Koike M, Takatsu K. Allergic diseases: from bench to clinic - contribution of the discovery of interleukin-5. Cytokine 98: 59-70, 2017.

14. Busse WW, Katial R, Gossage D, et al. Safety profile, pharmacokinetics, and biologic activity of MEDI-563, an anti-IL-5 receptor alpha antibody, in a phase I study of subjects with mild asthma. J Allergy Clin Immunol 125: 1237-1244, 2010.

15. Laviolette M, Gossage DL, Gauvreau G, et al. Effects of benralizumab on airway eosinophils in asthmatic patients with sputum eosinophilia. J Allergy Clin Immunol 132: 1086-1096, 2013.

The Internal Medicine is an Open Access journal distributed under the Creative Commons Attribution-NonCommercial-NoDerivatives 4.0 International License. To view the details of this license, please visit (https://creativecommons.org/licenses/ by-nc-nd/4.0/).

(C) 2020 The Japanese Society of Internal Medicine Intern Med 59: 1195-1198, 2020 